\title{
MMP-10, MMP-7, TIMP-1 and TIMP-2 mRNA expression in esophageal cancer
}

\author{
Agnieszka Juchniewicz'1, Oksana Kowalczuk¹, Robert Milewski², Wojciech Laudański³, Piotr \\ Dzięgielewski ${ }^{3}$, Mirosław Kozłowski ${ }^{3}$ and Jacek Nikliński1,3凶
}

1Department of Clinical Molecular Biology, Medical University of Bialystok, Bialystok, Poland; ${ }^{2}$ Department of Statistic and Medical Informatics, Medical University of Bialystok, Bialystok, Poland; ${ }^{3}$ Department of Thoracic Surgery, Medical University of Bialystok, Bialystok, Poland

\begin{abstract}
Introduction: Tissue inhibitors of metalloproteinases (TIMP) and the matrix metalloproteinases (MMP) are involved in the spread of cancer. Methods: We have evaluated the matrix metalloproteinases' (MMP-10, MMP-7) and their inhibitors' (tissue inhibitors of metalloproteinases - TIMP-1, TIMP-2) mRNA expression in 61 esophageal cancer samples from patients who had undergone surgery, by using real-time quantitative RT-PCR, and correlated the results with the patient clinicopathologic features. Results: MMP-10, MMP-7, TIMP-1, TIMP-2 were overexpressed in $73 \%, 85 \%, 55 \%$ and $42 \%$ of esophageal cancer samples, respectively. The expression of MMP-10, TIMP-1, and TIMP-2 correlated with the tumor size. The MMP-7 overexpression was associated with the tumour stage (I, II vs III, $\mathrm{p}=0.05$ ) and lymph node metastasis (NO vs $\mathrm{N} 1, \mathrm{p}=0.037)$. Conclusions: We conclude that in the resected esophageal cancer an increased mRNA expression of MMP-7, MMP-10 and TIMP-1 correlated with clinicopathologic features. We suggest that these genes may play a role during progression of the disease.
\end{abstract}

Key words: Esophageal cancer, gene expression, metalloproteinases

Received: 16 August, 2016; revised: 12 January, 2017; accepted: 01 February, 2017; available on-line: 15 May, 2017

e-mail: niklinsj@umb.edu.pl

Abbreviations: ESCC, esophageal carcinoma; MMP, matrix metalloproteinases; TIMP, tissue inhibitors of metalloproteinases

\section{INTRODUCTION}

Esophageal carcinoma (ESCC) is one of the leading causes of cancer death worldwide and causes an estimated 400000 deaths per year all over the world (Lozano et al., 2012). ESCC is characterized by an extensive local invasion, poor prognosis, and rapid clinical progression with a high frequency of lymph node metastasis and recurrence after treatment (Vallböhmer et al., 2010). Due to this aggressive nature and the lack of a screening strategy to detect an early stage of the disease, the prognosis of ESCC is even worse than other digestive tract cancers (Bollschweiler \& Hölscher, 2007; Kollarova et al., 2007).

One of the key steps during invasion and metastasis of ESCC, are structural changes in the extracellular matrix and degradation of the connective tissue surrounding the tumor cells, mediated by the matrix metalloproteinases (MMP) (Lynch \& Matrisian, 2002). Matrix metalloproteinases are a family of zinc-containing enzymes which are associated with tissue destruction under various pathologic conditions (Deryugina \& Quigley, 2006; Rydlova et al., 2008). MMP have been found to be over- expressed in a variety of epithelial and mesenchymal tumors, such as liver, renal, colon and esophagus (Leeman et al., 2003; Zhang et al., 2005; Miyata et al., 2006). High expression level of MMPs has been correlated with the tumor aggressiveness and unfavorable prognosis (Szarvas et al., 2010). MMPs are produced by the tumor cells themselves, and exhibit a broad and strong proteolytic activity against a variety of components of the ECM, such as collagens, vitronectin, gelatin, lamin, fibronectin, and proteoglycans (Visse \& Nagase, 2003).

Tissue inhibitors of metalloproteinases (TIMP) are well-studied inhibitors of metalloproteinases which play an important role in tumor invasion and metastasis (Sato et al., 1992). TIMP consist of a family of four structurally related proteins and have direct effects on cellular behaviors, such as cell growth, migration, differentiation, and apoptosis (Baker et al., 2002; Jian et al., 2002). An increased expression of matrix metalloproteinases and their tissue inhibitors is related to tumor aggressiveness and overall survival in various human malignancies (StetlerStevenson, 2001).

In the study presented here, we have evaluated the relationship between the matrix metalloproteinases' (MMP10, MMP-7) and their inhibitors' (tissue inhibitors of metalloproteinases - TIMP-1, TIMP-2) mRNA expression, and the clinicopathological features of patients with esophageal carcinoma.

\section{METHODS}

Patients and tissues. Tumor specimens were obtained from 61 patients with primary esophageal cancer (29 - esophageal squamous cell carcinoma, 32 - adenocarcinoma of the esophagus), who underwent an esophagectomy at the Department of Thoracic Surgery of the Medical University of Bialystok. None of them had received a preoperative chemotherapy or radiotherapy. The study population consisted of 56 men $(91.8 \%)$ and 5 women $(8.2 \%)$. The average age at the time of diagnosis was 64.0 years (ranged from 44 to 82 years). The pathological stage was based on AJCC TNM classification (7th edition) (Edge et al., 2010). All patients were followed up clinically after the surgery. Evaluations were performed every 3-6 months by means of a clinical history, physical examination, laboratory analysis, fiber-optic esophagoscopy, ultrasound examination of the neck and abdomen, barium esophagram, computed tomography, EUS, PET-CT and EBUS, if necessary. The average follow-up time was 33 months (ranged from 5 to 101 months). Nonmalignant esophageal tissues were collected as control specimens (Juchniewicz A. et al, 2015). 
Table 1. Assays analyzed in this study.

According to the aHUGO gene nomenclature committee and ${ }^{b}$ Applied Biosystems Life Technologies

\begin{tabular}{llll}
\hline Gene symbol & Official gene product name & Gene ID & Assay ID ${ }^{\mathrm{b}}$ \\
\hline MMP10 & Matrix metalloproteinases 10 (stromelysin 2) & 7156 & Hs00233987_m1 \\
\hdashline MMP 7 & Matrix metalloproteinases 7 (matrilysin, uterine) & 11820 & Hs01042796_m1 \\
\hline TIMP 1 & Tissue inhibitors of metalloproteinases 1 & 11821 & Hs01091319_m1 \\
\hline TIMP 2 & Tissue inhibitors of metalloproteinases 2 & \\
\hline
\end{tabular}

RNA extraction and cDNA synthesis. Tissue samples were collected intraoperatively. After the macroscopic visual assessment, the pieces of tumor tissue and unaffected esophageal tissue were frozen in liquid nitrogen, followed by storage at $-80^{\circ} \mathrm{C}$. Sections $(4 \mu \mathrm{m})$ of frozen tissue specimens were cut and stained with hematoxylin and eosin for verification of the presence of carcinoma cells (Cryotome FSE, Thermo Scientific, UK). These tissue samples were assessed by experienced pathologists. Only the tumor samples which contained at least $50 \%$ of tumor cells in a microscopic section were used for further processing.

Total RNA from tissue specimens was isolated and purified using a mirVana ${ }^{\mathrm{TM}}$ miRNA Isolation Kit (Ambion $^{\mathbb{R}}$, Austin, TX, USA) following the manufacturer's protocols. The resulting RNA extracts were stored at $-80^{\circ} \mathrm{C}$ before further processing. RNA quantity was assessed using a NanoDrop 2000c Spectrophotometer (Thermo Fisher Scientific, Wilmington, DE, USA). RNA quality, both 28S/18S ratio and RNA integrity number (RIN), was measured by using an Agilent 2,100 Bioanalyzer (Serial No DE72905449, Agilent Technologies Inc., CA, USA) and an RNA 6,000 Nano Assay Kit (Agilent Technologies Inc., CA, USA), according the manufacturer's recommendations. One microgram of total RNA was reverse-transcribed into cDNA. cDNA synthesis was performed using a High Capacity RNA-to-cDNA Master Mix with No RT Control (Applied Biosystems ${ }^{\text {TM }}$, Foster City, CA, USA), according to the manufacturer's instructions, and the Labcycler thermocycler (Sensoquest $\mathrm{GmbH}$, Göttingen, Germany) (Juchniewicz A. et al, 2015).

mRNA Expression level. An mRNA expression level of the matrix metalloproteinases (MMP-10, MMP-7) and their receptor genes (TIMP-1, TIMP-2) were evaluated in the tumor and the corresponding unaffected esophageal tissues, by the comparative real-time PCR (RT-PCR) method using commercially available TaqMan Gene Expression assays (Applied Biosystems ${ }^{\mathrm{TM}}$ ) (Table 1). Amplification was performed with a $20 \mu \mathrm{l}$ reaction mixture containing $10 \mu \mathrm{l}$ TaqMan Gene Expression Master Mix (Applied Biosystems ${ }^{\mathrm{TM}}$, Foster City, CA, USA), 1 $\mu$ l of the appropriate TaqMan Gene Expression assay solution and $2 \mu \mathrm{l}$ of the cDNA solution. Cycle conditions were as follows: $50^{\circ} \mathrm{C}$ for $2 \mathrm{~min}$, followed by $95^{\circ} \mathrm{C}$ for $10 \mathrm{~min}$, hold and 40 cycles of $95^{\circ} \mathrm{C}$ at $15 \mathrm{~s}$ and $60^{\circ} \mathrm{C}$ for $1 \mathrm{~min}$. Each sample was analyzed in triplicate. The reaction was conducted with an ABI PRISM 7900HT Sequence Detection System (Applied Biosystems, Foster City, CA, USA) equipped with the SDS v.2.4 software for baseline and cycle threshold (Ct) calculations. Gene transcript levels were quantified as $\mathrm{Ct}$ values, normalized for the differences in the input cDNA amount by subtraction of the $\mathrm{Ct}$ value of the $18 \mathrm{~S}$ rRNA reference gene $\left(\Delta C_{t}=C_{t \text { gene }}-C_{t \text { ref }}\right)$. Gene expression levels were inversely proportional to the $\Delta C_{t}$ values and were based on a $\log _{2}$ scale. The reaction mixture and cycle conditions for the $18 \mathrm{~S}$ rRNA cDNA amplification were the same as those described for the matrix metalloproteinases (MMP10, MMP-7) and their receptors' (TIMP-1, TIMP-2) amplification.

Tumor-associated fold-change (FC) in the mRNA level

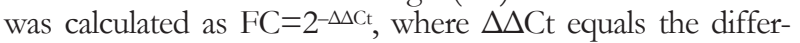
ence between the normalized expression of the gene in the tumor $\left(C_{t \text { gene } T}\right)$ and its normalized expression in the corresponding nonmalignant esophageal tissue $\left(\mathrm{C}_{t \text { tgene }}\right)$ from the same patient (Schmittgen \& Livak, 2008). For the statistical analysis, logarithmically transformed FC values were used $\left(\log _{2}(\mathrm{FC})\right)$. The $\log _{2}(\mathrm{FC})$ value equaled 1.0 was used as a threshold to categorize samples into two groups with low $\left(\log _{2}(\mathrm{FC})<1.0\right)$ and high $\left(\log _{2}(\mathrm{FC})>1.0\right)$ gene expression.

Statistical analysis. Due to asymmetric data distribution (Shapiro-Wilk tests) non-parametric tests were performed. Categorical data was compared by the $\lambda^{2}$ or Fisher's exact probability test. The $p$ value of less than 0.05 was considered to be significant. Statistical analyses were carried out using the Statistica 10.0 PL program (StatSoft Inc., Tulsa, OK, USA) and the Stata/IC 12.1 (StataCorp LP, Texas, USA)

In accordance with the Declaration of Helsinki, the study protocol was approved by the local Ethics Committee (No R-1-002/28/2010) and written informed consent was obtained from all participants prior to analysis.

\section{RESULTS}

An increased expression of MMP-10 mRNA was observed in tumor samples from $45(73.77 \%)$ patients, and MMP-7 mRNA level was increased in 52 (85.25\%) patients (Table 2). Expression of MMP-10 correlated with the patients' age and tumor size. There were no associations between the MMP-10 mRNA expression level and sex, histological type, tumor stage, lymph node metastasis, depth of tumor invasion and location, histological grade and residual tumor. The MMP-7 overexpression was associated with the tumor stage and lymph node metastasis. In cancerous tissues, high expression level of TIMP-1 mRNA was observed in $55.74 \%$ of patients, and TIMP-2 mRNA in $42.62 \%$ of patients. The TIMP-1 and TIMP-2 expression level had a significant relationship with tumor size.

\section{DISCUSSION}

The development of malignant neoplasms is a multistep process which results in rapid growth and invasion of the tumor cells into lymphatic and blood vessels. The first step of the tumor development and metastasis is associated with degradation of the extracellular matrix, which leads to proteolysis of microvessel basement membranes, invasion of endothelium and migration of malignant cells (Samantaray et al., 2004). Some studies indicate that MMP and their inhibitors have been reported to appear closely associated with the tumor invasion, 
Table 2. Association between mRNA expression and clinicopathological criteria

†Fisher's exact test; ${ }^{\ddagger} \chi^{2}$ test; MMP-10 matrix metalloproteinase-10, MMP-7 matrix metalloproteinase-7, TIMP-1 tissue inhibitor of metalloproteinases-1, TIMP-2 tissue inhibitor of metalloproteinases-2, Sqcc-squamous cell carcinoma; Adc-adenocarcinoma; G1-well differentiated; G2- moderately differentiated; G3-poorly differentiated; T1-tumor invades lamina propria or submucosa; T2-tumor invades muscularis propria; T3-tumor invades adventitia; T4-tumor invades adjacent structures; N0-no regional lymph node metastases; N1-regional lymph node metastases, R0-no residual tumor; R1-microscopic residual tumor; R2-macroscopic residual tumor

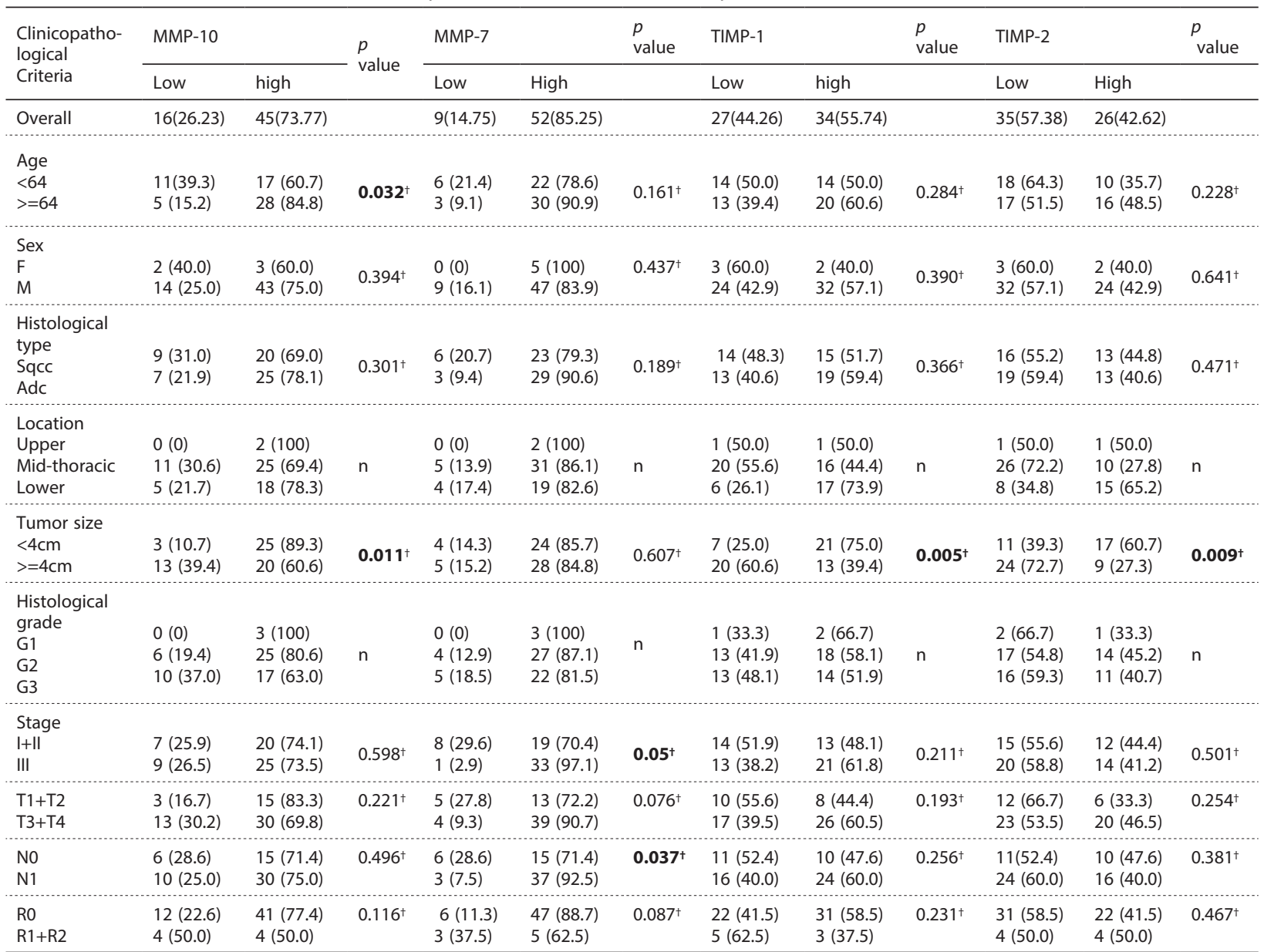

metastasis and prognosis in patients with esophageal cancer (Yamashita et al., 2000; Gu et al., 2005). The aim of the study presented here, was to analyse the mRNA expression levels of MMP-7, MMP-10, TIMP-1, TIMP2 , and the clinicopathological features of patients with esophageal cancer.

We have observed overexpression of MMP-7, MMP10, TIMP-1, TIMP-2 in the tumor tissues. Our findings are in accordance with the findings of Yamashita and coworkers and Zhou and coworkers who have shown through immunohistochemistry, western blot, and RTPCR assays that MMP-7 was overexpressed in the esophageal tumor cells (Yamashita et al., 2000; Zhou et al., 2011). Mukherjee et al had shown by using quantitative RT-PCR and gelatin zymography that levels of the MMP-10 protein and its mRNA expression were higher in the esophageal cancer cells than in the corresponding normal tissues (Mukherjee et al., 2010). Studies indicate that some stromal-derived factor might stimulate the MMP expression. Borchers and coworkers had demonstrated that the fibroblast - derived cytokine growth factors seem to enhance expression of the MMP-7 in ESCC (Borchers et al., 1994).

Here, we have found that the MMP-7 mRNA overexpression associated with the tumor stage and lymph node metastasis. This is in accordance with studies by Yamashita and coworkers and Tanioka and coworkers who have reported that the MMP-7 mRNA expression was related to the nodal metastasis and prognosis (Yamashita et al., 2000; Tanioka et al., 2003). Yamanato and coworkers had demonstrated by immunohistochemical techniques that the MMP-7 mRNA expression level was related to an advanced tumor stage and a worse prognosis (Yamamoto et al., 1999).

The effects of TIMPs on esophageal tumorigenesis are multifunctional and paradoxical. TIMPs are considered to be inhibitors of tumor development, as well as growth factors. The imbalance between MMPs and their inhibitors may facilitate progression of cancer cells (Kähäri et al., 1999; Nabeshima et al., 2002). In the study presented here, the TIMP-1 mRNA expression level was observed to be increased in $55.7 \%$ of ESCC cases, whereas TIMP-2 was increased in 42.6\%. Mroczko and coworkers had shown that patients with gastric cancer had higher TIMP-1 serum levels than the healthy subjects (Mroczko et al., 2009). Salmela and coworkers had shown that TIMP-1 was overexpressed in $80 \%$ of esophageal tumor cells (Salmela et al., 2001).

Mroczko and coworkers had found that the serum TIMP-1 significantly correlated with the depth of 
the tumor invasion, lymph node metastases, and distant metastases in gastric cancer and pancreatic cancer (Mroczko et al., 2009; Mroczko et al., 2009). Moreover, Mimori and coworkers had demonstrated that the primary gastric carcinomas with high TIMP-1 expression have shown a higher grade malignant potential (Mimori et al., 1997). In esophageal cancer, Mori and coworkers observed a higher frequency of lymph node metastasis and advanced disease stage with poorer prognosis in high TIMP-1 mRNA expression cases (Mori et al., 2000). Kozlowski and coworkers had shown a significant association between the tumor depth, advanced stage, lymph node metastasis and serum concentration of TIMP-1 in the esophageal cancer patients (Kozłowski et al., 2013). A multivariate analysis expression of TIMP-1 was an independent prognostic factor for overall survival in resected EC patients (Mori et al., 2000). Sharma and coworkers had shown the prognostic significance of TIMP-1 and TIMP-2 immunostaining in ESCC in relation to invasion, tumor progression, and metastasis (Sharma et al., 2004). Patients with TIMP-2 negative carcinoma had a significantly shorter disease free survival in comparison with the TIMP-2 positive tumors (Sharma et al., 2004). Similar results were obtained by Alakus and coworkers who had suggested that aggressive forms of gastric cancer are associated with low TIMP-2 expression. In their study, the TIMP-2 levels were lower in more advanced tumor stages than in the early stages I+II (Alakus et al., 2008). In the study presented here, the TIMP-1 and TIMP-2 expression were not found to be a significantly independent prognostic factor (data not shown).

In summary, the study presented here demonstrates that in the resected esophageal cancer, an increased mRNA expression of MMP-7, MMP-10 and TIMP-1 is correlated with clinicopathological features. We suggest that these genes may play a role during the progression of the disease and this issue requires further investigation.

\section{Acknowledgemets}

The study was financed by the National Science Centre (Poland) with the funds of grant no. N N403 282739

This study was conducted with the use of equipment purchased by the Medical University of Bialystok as part of the OP DEP 2007-2013, Priority Axis I.3, contract No POPW.01.03.00-20-022/09

This study was supported by the Medical University of Bialystok, Poland (grant no. 113-84-807L) and was partially conducted within the 'Cancer/Mutagenesis' research area of the Leading National Research Centre (KNOW).

\section{REFERENCES}

Alakus H, Grass G, Hennecken J, et al. (2008) Clinicopathological significance of MMP-2 and its specific inhibitor TIMP-2 in gastric cancer. Histol Histopathol 23: 917-923

Baker AH, Edwards DR, Murphy G. (2002) Metalloproteinase inhibitors: biological actions and therapeutic opportunities. J Cell Sci 115: 3719-3727. https://dx.doi.org/10.1242/jcs.00063

Bollschweiler E, Hölscher AH (2007) Prognosis of early esophageal cancer: differences between squamous cell carcinoma and adenocarcinoma. Ann Surg 245: 334-339. https://dx.doi.org/10.1097/01. sla.0000253072.33351.a4

Borchers AH, Powell MB, Fusenig NE, Bowden GT. (1994) Paracrine factor and cell-cell contact-mediated induction of protease and c-ets gene expression in malignant keratinocyte/dermal fibroblast cocultures. Exp Cell Res 213: 143-147. https://dx.doi.org/10.1006/ excr.1994.1183
Deryugina EI, Quigley JP. (2006) Matrix metalloproteinases and tumor metastasis. Cancer Metastasis Rev 25: 9-34. https://dx.doi. org/10.1007/s10555-006-7886-9

Edge SB, ByrD DR, Compton CC, Fritz AG, Greene FL, Trotti A. (2010) Esophagus and esophagogastric junction. In AJCC cancer staging manual. Edge SB, Byrd DR, Compton CC, Fritz AG, Greene FL eds. 7th edn, pp 103-107. New York: Springer

Gu ZD, Li JY, Li M, et al. (2005) Matrix metalloproteinases expression correlates with survival in patients with esophageal squamous cell carcinoma. Am J Gastroenterol 100: 1835-1843. https://dx.doi. org/10.1111/j.1572-0241.2005.50018.x

Jian GY, Goldberg ID, Shi YE (2002) Complex roles of tissue inhibitors of metalloproteinases in cancer. Oncogene 21: 2245-2252. https://dx.doi.org/10.1038/sj.onc.1205291

Juchniewicz A, Niklińska W, Kowalczuk O, et al. (2015) Prognostic value of vascular endothelial growth factor-C and podoplanin mRNA expression in esophageal cancer. Oncol Lett 10: 3668-3674. htpp:// doi.org/10.3892/ol.2015.3824

Kähäri VM, Saarialho-Kere U (1999) Matrix metalloproteinases and their inhibitors in tumour growth and invasion. Ann Med 31: 34-45

Kollarova H, Machova L, Horakova D, Janoutova G, Janout V. (2007) Epidemiology of esophageal cancer - an overview article. Biomed Pap Med Fac Univ Palacky Olomouc Czech Repub 151: 17-20

Kozłowski M, Laudański W, Mroczko B, Szmitkowski M, Milewski R, Lapuć G, (2013) Serum tissue inhibitor of metalloproteinase 1 (TIMP-1) and vascular endothelial growth factor A (VEGF-A) are associated with prognosis in esophageal cancer patients. Adv Med Sci 58: 227-234. https://dx.doi.org/10.2478/ams-2013-0017

Leeman MF, Curran S, Murray GI. (2003) New insights into the roles of matrix metalloproteinases in colorectal cancer development and progression. J Pathol 201: 528-534. https://dx.doi.org/10.1002/ path.1466

Lozano R, Naghavi M, Foreman K, et al. (2012) Global and regional mortality from 235 causes of death for 20 age groups in 1990 and 2010: a systematic analysis for the Global Burden of Disease Study 2010. Lancet 380: 2095-2128. https://dx.doi.org/ 10.1016/S01406736(12)61728-0

Lynch CC, Matrisian LM. (2002) Matrix metalloproteinases in tumor-host cell communication. Differentiation 70: 561-573. https:// dx.doi.org/10.1046/j.1432-0436.2002.700909.x

Mimori K, Mori M, Shiraishi T, et. al. (1997) Clinical significance of tissue inhibitor of metalloproteinase expression in gastric carcinoma. Br J Cancer 76: 531-536

Miyata Y, Iwata T, Ohba K, et al. (2006) Expression of matrix metalloproteinase- 7 on cancer cells and tissue endothelial cells in renal cell carcinoma: prognostic implications and clinical significance for invasion and metastasis. Clin Cancer Res 12: 6998-7003. https://dx.doi. org/10.1158/1078-0432.CCR-06-1626

Mori M, Mimori K, Sadanaga N, et al. (2000) Prognostic impact of tissue inhibitor of matrix metalloproteinase-1 in esophageal carcinoma. Int J Cancer 88: 575-578. https://dx.doi.org/10.1002/10970215(20001115)88:4<575::AID-IJC9>3.0.CO;2-C

Mroczko B, Groblewska M, Łukaszewicz-Zajac M, Bandurski R, Kedra B, Szmitkowski M. (2009) Pre-treatment serum and plasma levels of matrix metalloproteinase 9 (MMP-9) and tissue inhibitor of matrix metalloproteinases 1 (TIMP-1) in gastric cancer patients. Clin Chem Lab Med 47: 1133-1139. https://dx.doi.org/10.1515/ CCLM.2009.253

Mroczko B, Łukaszewicz-Zając M, Wereszczyńska-Siemiątkowska U, et al. (2009) Clinical significance of the measurements of serum matrix metalloproteinase-9 and its inhibitor (tissue inhibitor of metalloproteinase-1) in patients with pancreatic cancer: metalloproteinase- 9 as an independent prognostic factor. Pancreas 38: 613-618. https://dx. doi.org/10.1097/MPA.0b013e3181a488a0

Mukherjee S, Roth MJ, Dawsey SM, et al. (2010) Increased matrix metalloproteinase activation in esophageal squamous cell carcinoma. $J$ Transl Med 8: 91. https://dx.doi.org/10.1186/1479-5876-8-91

Nabeshima K, Inoue T, Shimao Y, Sameshima T (2002) Matrix metalloproteinases in tumor invasion: role for cell migration. Pathol Int 52: 255-264. https://dx.doi.org/10.1046/j.1440-1827.2002.01343.x

Rydlova M, Holubec LJR, Ludvikova MJR, et al. (2008) Biological activity and clinical implications of the matrix metalloproteinases. $A n$ ticancer Res 28: 1389-1397

Salmela MT, Karjalainen-Lindsberg ML, Puolakkainen P, SaarialhoKere U (2001) Upregulation and differential expression of matrilysin (MMP-7) and metalloelastase (MMP-12) and their inhibitors TIMP-1 and TIMP-3 in Barrett's esophageal adenocarcinoma. $\mathrm{Br} \mathrm{J}$ Cancer 85: 383-392. https://dx.doi.org/10.1054/bjoc.2001.1929

Samantaray S, Sharma R, Chattopadhyaya TK, Gupta SD, Ralhan R (2004) Increased expression of MMP-2 and MMP-9 in esophageal squamous cell carcinoma. I Cancer Res Clin Oncol 130: 37-44. https://dx.doi.org/10.1007/s00432-003-0500-4

Sato H, Kida Y, Mai M, Endo Y, Sasaki T (1992) Expression of genes encoding type IV collagen-degrading metalloproteinases and tissue inhibitors of metalloproteinases in various human tumor cells. Oncogene 7: 77-83 
Schmittgen TD, Livak KJ (2008) Analyzing real-time PCR data by the comparative C(T) method. Nat Protoc 3: 1101-1108

Sharma R, Chattopadhyay TK, Mathur M, Ralhan R (2004) Prognostic significance of stromelysin-3 and tissue inhibitor of matrix metalloproteinase-2 in esophageal cancer. Oncology 67: 300-309. https:// dx.doi.org/10.1159/000081331

Stetler-Stevenson WG (2001) The role of matrix metalloproteinases in tumor invasion, metastasis, and angiogenesis. Surg Oncol Clin $N A m$ 10: 383-392

Szarvas T, Becker M, Vom Dorp F, et al. (2010) Matrix metalloproteinase- 7 as a marker of metastasis and predictor of poor survival in bladder cancer. Cancer Sci 101: 1300-1308. https://dx.doi. org/10.1111/j.1349-7006.2010.01506.x

Tanioka Y, Yoshida T, Yagawa T, et al. (2003) Matrix metalloproteinase-7 and matrix metalloproteinase- 9 are associated with unfavourable prognosis in superficial oesophageal cancer. $\mathrm{Br} J$ Cancer 89: 2116-2121. https://dx.doi.org/10.1038/sj.bjc.6601372

Vallböhmer D, Brabender J, Metzger R, Hölscher AH (2010) Genetics in the pathogenesis of esophageal cancer: possible predictive and prognostic factors. J Gastrointest Surg 14: 75-80. https://dx.doi. org/10.1007/s11605-009-1021-5
Visse R, Nagase H (2003) Matrix metalloproteinases and tissue inhibitors of metalloproteinases: structure, function, and biochemistry. Circ Res 92: 827-839. https://dx.doi.org/10.1161/01. RES.0000070112.80711.3D

Yamamoto H, Adachi Y, Itoh F, et al. (1999) Association of matrilysin expression with recurrence and poor prognosis in human esophageal squamous cell carcinoma. Cancer Res. 59(14): 3313-3316.

Yamashita K, Mori M, Shiraishi T, Shibuta K, Sugimachi K (2000) Clinical significance of matrix metalloproteinase- 7 expression in esophageal carcinoma. Clin Cancer Res 6: 1169-1174

Zhang J, Jin X, Fang S, et al. (2005) The functional polymorphism in the matrix metalloproteinase-7 promoter increases susceptibility to esophageal squamous cell carcinoma, gastric cardiac adenocarcinoma and non-small cell lung carcinoma. Carcinogenesis 26: 1748-1753. https://dx.doi.org/10.1093/carcin/bgi144

Zhou JH, Zhang B, Kernstine KH, Zhong L. (2011) Autoantibodies against MMP-7 as a novel diagnostic biomarker in esophageal squamous cell carcinoma. World J Gastroenterol 17: 1373-1378. https:// dx.doi.org/10.3748/wjg.v17.i10.1373 